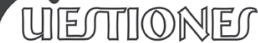

Constitucionales

Revista Mexicana de Derecho Constitucional

Núm. 24, enero-junio 2011

\section{DISCURSO DEL MAGISTRADO JUAN LUIS GONZÁLEZ ALCÁNTARA, EN EL MARCO DEL DÉCIMO ANIVERSARIO DE LA REVISTA CUESTIONES CONSTITUCIONALES}

Muy buenas tardes tengan todos ustedes.

Seguramente, la antípoda de la palabra escrita y la palabra hablada. Frente al libro, la retórica. Cuando recibí la invitación, honrosa a mi juicio, para participar en esta ceremonia con tan ilustres juristas, por azares del destino terminaba de releer la obra de Marco Tulio Cicerón titulada de Optimo genere oratorum. No hace falta referirme a detalle a los pormenores del libro de Cicerón, basta decir, que al defender su oratoria, otorga a sus jóvenes adversarios una serie de consejos que por su precisión bien pueden aplicarse a la literatura, al arte, a la ciencia o al derecho.

Efectivamente, aludiendo al orador, se refiere a sí mismo, al escritor, al artista, al científico. Si el discurso consta de palabras y de pensamientos, unos y otros necesitan de una adecuada disposición, para ser capaz de trasmitir el mensaje y lo mismo acontece en la literatura, en el arte, en el derecho, ya que también necesitan pensamientos y palabras adecuadamente estructurados para comunicar el conocimiento, así que, lo que predica Cicerón, es el fundamento de toda comunicación humana.

Asistimos hoy a un acto que en sí mismo es extraordinario, diez años de la publicación ininterrumpida de la colección intitulada Cuestiones Constitucionales. Aparece en julio de 1999.

El doctor Diego Valadés presenta el primer tomo, significativo resulta releer la oración post firma, dice así:

en las afueras de Ciudad Universitaria, julio de 1999. Recordemos que nuestra Universidad, la Universidad de todos, la Universidad de México, se encontraba tomada, se decidía su futuro, los ánimos, los sentimientos, estaban a flor de piel, y aún así se prologaba a fuera de las instalaciones universitarias el primer tomo de Cuestiones Cons- 
titucionales. Parto difícil, pero como se anunciaba entonces, una publicación que ha llenado un gran vacío en nuestro país.

La Universidad Nacional Autónoma de México trasciende a sus inmuebles, al campus universitario. Se encuentra en el interior de los universitarios, entre corazón y mente, ahí se ubica.

Hecho inusitado también, porque en un país en que la lectura se ve como algo arcaico, ha logrado subsistir. Los libros tienen algo mágico y a la par, su existencia depende de su lectura, de que sean usados por otros que al posar sus ojos sobre sus pensamientos y palabras adecuadamente estructurados, sean capaces de recrear el conocimiento: ahí su magia. Con precisión, Cuestiones Constitucionales subsiste porque es leída y comentada, no hay más.

La comunicación humana utiliza distintos medios para implantarse, existe la televisión, el internet, la comunicación satelital, todos ellos cuya característica es la difusión a las grandes masas. Conjuntamente están los libros, las revistas, los periódicos; tan importantes como los primeros, pero si se me permite la osadía, dirigido a un público más selecto, al hombre que piensa, que analiza que critica, que crea.

José Ortega y Gasset realiza una distinción señera ente el libro y la revista, y como estamos festejando a nuestra revista Cuestiones Constitucionales, deseo compartir con ustedes el pensamiento del filósofo español.

En la Gaceta Literaria, en los años veinte, nos dice que el libro es una obra completa, acabada, desprendida y ajena a su autor, encerrada en sí, pequeño astro de realidad. El autor al publicar su obra tiene la impresión de que ha enajenado un trozo de sí mismo, que ya no le pertenece, que el libro se ha nutrido en el secreto habiente de sus ideas, preferencias, postulados. Sólo el autor conoce ese secreto que es la clave decidida del libro. El libro en sí, en su plenitud es completo y basto, de ahí que las palabras introductorias del doctor Valadés al primer tomo de la revista, son precisas, intachables, al manifestar que con independencia de la calidad de muchos constitucionalistas mexicanos no tenemos un solo tratado de Derecho Constitucional. Carecemos de ese libro, astro de realidad, que irradie ases que contemplen la totalidad del derecho constitucional mexicano.

Pero retornemos a Ortega y Gasset, para él la revista se nutre de juicios tiernos, de curiosidades, de insinuaciones, de ideas y pensamientos en gestación. En la revista, el autor arriesga más, precisamente porque en su 
texto encontramos lo recóndito de su pensamiento, la discusión íntima, verdadera y autentica, en la dialéctica de sus ideas.

Ortega y Gasset termina diciendo: "nos gusta el libro cuando es miel, mas por lo mismo, nos gustaría asistir a la melificación, ver el temblor de las abejas en sus corsés de oro. ¡Qué fabulosa y educación mutuas produce una revista así escrita al oído!".

A mi entender, Cuestiones Constitucionales tiene eso que Ortega y Gasset, llama "melificación", el proceso íntimo del análisis del autor, su pensamiento inacabado, no porque esté falto de método o de técnica o que no se agote el tema; sino que, el lector vislumbra con el autor que sobre ese tema puede escribirse más y con mayor profundidad.

La producción de las revistas jurídicas a nivel mundial, se distinguen por ese rasgo de osadía, al reproducir en sus páginas el pensamiento novedoso entorno a Instituciones Jurídicas, el comentario y análisis que desde la academia se realiza a la Corte Constitucional o la invitación al lector de conocer nuevo libro mediante la sinopsis del mismo, por todo ello, tales revistas cuentan con un peso específico en el mundo de lo jurídico.

Nuestra revista Cuestiones Constitucionales cuenta con las anteriores características, por ello, me congratulo de estar presente en esta ceremonia. Felicito a su fundador y actual Director, al doctor Edgar Corzo Sosa, por su constancia, por su osadía, por atreverse a ser diferente. Sólo los que hemos sudado la tinta, sabemos de los desvelos, de la crispación de los nervios, del cuidado que se pone en la edición para que a la postre ésta no sea perfecta, un punto mal puesto, una coma innecesaria, un tiempo del verbo utilizado adecuadamente; así son los libros, como el hombre, no hay libro perfecto, pues en su etimología lleva su destino. Libro proviene del latín: líber, libri, membrana, corteza de árbol, es producto de un parto de un ser vivo, tanto material como espiritualmente y en consecuencia, presenta imperfecciones.

Felicito a todos aquellos que han publicado en la revista, nacionales y extranjeros, su participación ha contribuido para engrandecerla; felicito a sus miles de lectores; felicito finalmente al Tribunal Superior de Justicia del Distrito Federal y en especial a su presidente el doctor Edgar Elías Azar. Eventos como este son necesarios para acabar de formar el carácter de los jueces, su idoneidad cultural, ya que si vivimos en un Estado constitucional de derecho, es la Constitución la que da cohesión y sentido al 
Estado mismo y cualesquier acto que atente contra los principios básicos de la norma suprema, deberá ser expulsado del ordenamiento jurídico por un Tribunal ad hoc, que no es otro que el Tribunal Constitucional.

Mucha tinta se ha gastado, mucha retórica se ha utilizado para que nuestro país finalmente cuente y se instaure un Tribunal Constitucional; parecería ser que todos estamos de acuerdo, con excepción de algunos ministros de la Suprema Corte de Justicia de la Nación. Dejemos a los tribunales colegiados el control de la legalidad y concentremos en la Suprema Corte de Justicia el control constitucional. De no hacerse en nuestro ámbito, seguirá reinando la sempiterna discusión, nacida en el siglo pasado y concretizada entre Kelsen y Smith, en torno al normativismo y al decisionismo, es decir, al ente encargado del control constitucional. En teoría política existe la máxima de que el espacio del poder no colmado por uno, es otro el que lo llena. Si nuestra Corte no asume en definitiva su responsabilidad, llevando hasta las últimas consecuencias la reforma constitucional gestada en 1994, mucho me temo que otro poder la asumirá.

Cicerón a los 15 años de edad, escribió su tratado de inventione, en su edad madura miraba con desdén su juvenil creación. Consideraba que no era la invención la principal y más grande parte de la retórica; sin embargo, no modifica su infantil actitud ante algo más profundo, la moral del orador, en el decurso de su vida aprendió, convenció y practicó la mejor forma de persuadir, pronunció profundos y conceptuosos discurso, contra Verres o Catilina, pero lo significativo, lo trascendente que a mi juicio tiene Cicerón, se encuentra en sus oraciones, las más autenticas, las más humanas, realizadas en la lucha contra Antonio, en ellas no hay palabras ordenadas sobre la base de la ciencia del estilo, sino la profunda manifestación de la postura ética basada en el deber cumplido. Empecé con Cicerón y termino con él, recordando que existe en materia judicial un deber incumplido, que reclama la ética pública, la creación en definitiva de la Suprema Corte de Justicia como Tribunal Constitucional. 